Reprod. Nutr. Dévelop. 1980, 20 (4 A), 1051-1060.

\title{
The influence of some pterins on the circadian rhythmicity of hydroxyindole-O-methyl transferase in the pineal gland of 42-day old male Wistar rats
}

\author{
par M. G. M. BALEMANS $\left({ }^{1}\right)$, J. Van BENTHEM, W. C. LEGERSTEE, A. de MOREE *, \\ H. J. P. M. NOTEBORN *, I. EBELS * \\ Zoological Laboratory, Section of Histology and Cell Biology, \\ * Laboratory for Orgonic Chemistry, \\ State University of Utrecht, Utrecht, The Netherlands.
}

Summary. The influence of three pierin derivatives on the diurnal fluctuations of HIOMT (hydroxyindole-0-methyl transferase) activity was studied in the isolated pineal glands of 42-day old male Wistar rats during the month of October.

The method used permitted the separate determination of four HIOMT activities.

- Reduced neopterin stimulated the methylation of the substances, 5-HTP, 5-HT and 5-HIAA (see abbreviations in Material and methods), during the night. HIOMT action on the combinations N-Ac-5-HT/5-HTL was shifted to a later moment in the dark period.

- Pterin-6-aldehyde stimulated HIOMT action on 5-HT during the daytime. HIOMT action on the substrates 5-HTP, 5-HIAA and $\mathrm{N}-\mathrm{Ac}-5-\mathrm{HT} / 5-\mathrm{HTL}$ was shifted towards an earlier period.

- Isoxanthopterin did not exert any influence on diurnal variation in the four HIOMT activities.

It may be concluded that reduced neopterin and pterin-6-aldehyde influenced the activity and the circadian rhythmicity of 5-methoxyindole synthesis.

Those alterations might be important in the regulation of reproduction.

\section{Introduction.}

After Klein et al. (1970) and Klein and Weller (1970) discovered that N-acetyltransferase was stimulated in the dark by norepinephrine and CAMP, much attention was given to the regulation of that enzyme. The data from these investigations suggested that there was little or no regulation of the next step of melatonin synthesis, the methylation of N-acetylseroionin by HIOMT. This led Klein ef al. (1970) to suggest that HIOMT-induced melatonin synthesis depended only on the « mass action of $\mathrm{N}$-acetylserotonin ».

(1) Author's address : Dr. M. G. M. Balemans, Zoological Laboratory, Transitorium III, Padualaan 8. Utrecht, The Netherlands. 
However, some data on HIOMT regulation have been put forward in the literature. HIOMT activity, which is also maximal during the dark period (Axelrod et al., 1965), is suppressed by norepinephrine (Weiss, 1968). An identical effect was obtained by Brownstein and Heller (1968) after nerve stimulation. It is remarkable that these effects are opposite to the data on $\mathrm{N}$-acetyltransferase activity. On the other hand, the application of parasympathomimetic drugs suggested that acetylcholine was involved in the stimulation of HIOMT activity (Wartman ef al., 1969). It is therefore possible that the activities of both $\mathrm{N}$-acetyltransferase and HIOMT are regulated by the nervous system.

It has been suggested recently that HIOMT activity is also regulated by pteridines. Cremer-Bartels and Hollwich (1978) observed that certain pteridines decreased HIOMT activity in rat and bovine retina and pineal gland. In bovine and rabbit retina Cremer-Bartels and Hockwin (1963) demonstrated the presence of a pteridine-ribosephosphate complex whose metabolism was higher in light than in darkness. These investigations may indicate an inhibition of melatonin synthesis by certain pteridines during the daytime.

The presence of pteridines in the pineal (Van der Have-Kirchberg et al., 1977) and their higher content there than in other organs (Fukushima and Nixon, 1979 ; Levine ef al., 1979), their involvement in indole metabolism as a cofactor of tryptophan hydroxylase (Lovenberg and Victor, 1974), and their influence on HIOMT activity (Cremer-Bartels and Hollwich, 1978) all suggest that the pteridines could be of importance in regulating the metabolism of melatonin and/or 5-methoxytryptophol, two 5-methoxyindoles implicated in the regulation of reproduction (Wurtman et al., 1963 ; Mclsaac et al., 1964).

In the present study three synthetic pterins (2-amino, 4-oxo-pteridines) - reduced neopterin, pterin-6-aldehyde and isoxanthopterin-were tested for their influence on the circadian rhythmicity of various HIOMT activities synthesizing several 5-methoxyindoles.

\section{Material and methods.}

Experiments were performed in October on 42-day old male Wistar rats of 180 to $200 \mathrm{~g}$ given about 320 Lux of light between $8 \mathrm{a}$. m. and $8 \mathrm{p}$. m. and kept in darkness between $8 \mathrm{p}$. $\mathrm{m}$. and $8 \mathrm{a}$. $\mathrm{m}$. The animal room was maintained at a temperature of $23^{\circ} \mathrm{C}$ and 60 p. 100 relative humidity. Water and food were given ad libitum.

Twelve animals were decapitated every $4 \mathrm{hrs}$ and their pineals excised during the daytime in daylight and at night under red light, according to Cardinali ef al. (1972) who showed that HIOMT was less inhibited in red light than in daylight. Three of the excised pineals were incubated separately for $30 \mathrm{~min}$ with reduced neopterin and three with pterin-6-aldehyde ; the other six pineals were incubated separately in the solvent system only. All incubations were carried out in darkness. After this incubation period, the methylating capacity of each pineal was determined using the method of Balemans ef al. (1978). In this method no substrate is used. The following hydroxyindoles present in the pineal were methylated and quantified : 5-hydroxytryptophan (5-HTP), 5-hydro- 
xytryptamine (5-HT), 5-hydroxyindole-3-acetic acid (5-HIAA) and the combination of $\mathrm{N}$-acetylserotonin with 5-hydroxytryptophol (5-HTL) (fig. 1).

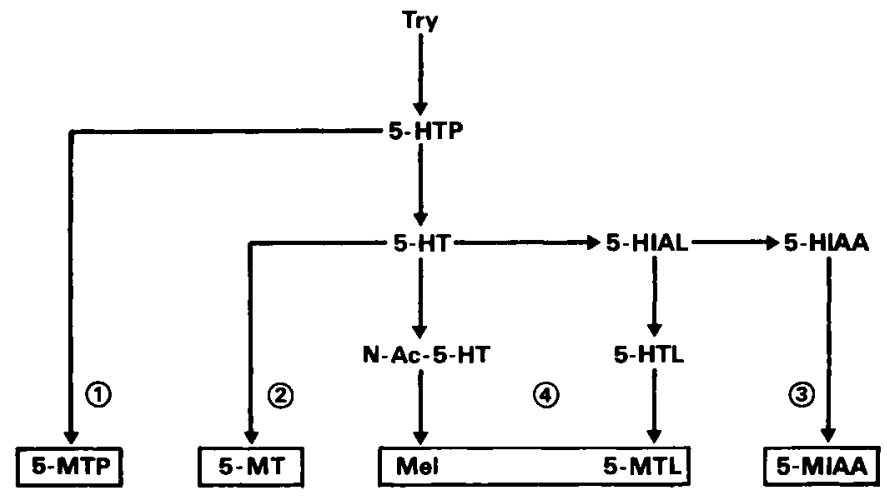

FIG. 1. - Methylations found with the method used in this study : (1) : methylation of 5-hydroxytryptophan (5-HTP) to 5-methoxytryptophan (5-MTP). (2) : methylation of 5-hydroxytryptamine (5-HT) to 5-methoxytryptamine (5-MT). (3) : methylation of 5-hydroxyindole-3-acetic acid (5-HIAA) to 5-methoxyindole-3-acetic acid (5-MIAA). (4) : methylation of the combination of $\mathrm{N}$-acetylserotonin/ 5-hydroxytryptophol (N-Ac-5-HT/5-HTL) to melatonin/5-methoxytryptophol (mel/5-MTL). Try = tryptophan ; 5-HIAL = 5-hydroxyindole aceetaldehyde.

An identical procedure was used with isoxanthopterin. The pineals of three rats were incubated separately with this pterin, and three pineals were also incubated separately with the solvent only.

Pferins (2-amino, 4-oxo-pteridines). - The pterins were prepared as much as possible in darkness to avoid their decomposition. Dim red light was used when needed.

Reduced neopterin (fig. 2). - Dihydroneopterin was synthesized from D-neopterin (Fluka AG, Chemische Fabrik, CH-9470, Switzerland) according to the method of Kaufman (1967). Tetrahydroneopterin was synthesized from D-neopterin according to the method of Lloyd and Weiner (1971). The pterins were trimethylsilylated tomake them suitable for gas-liquid chromatography, as described by Van derHave-Kirchberg ef al. (1977). The purity of the synthetic pterins after trimethylsilylation was controlled with a Varian Aerograph 3740. As column material, we used 1.5 p. 100 dexil $300 \mathrm{GC}$ on gaschrom Q, 60-80 mesh or 3.8 p. 100 SE-30 cm chromosorb W-HP, 80-100 mesh. Combined gas-liquid chromatography-mass spectrometry (GL-MS) was carried out on a Hewlett Packard 5710 A/Jeol JMS-D 300 combination ; $70 \mathrm{eV}$ mass spectra were recorded at an ion source temperature of $200^{\circ} \mathrm{C}$. The JMS-D 300 mass spectrometer was equipped with a Jeol JMA-2000 mass data analysis system.

Application of the methods of Kaufman (1967) and Lloyd and Weiner (1971) did not give the pure compounds as expected. Kaufman (1967) reported the synthesis of dihydroneopterin, and Lloyd and Weiner (1971) proposed that their preparation was tetrahydroneopterin. Results on the control of the structure with UV absorbancy were confirmed for both substances. However, when GC-MS was used, our data differed 
from the results of Kaufman (1967) and Lloyd and Weiner (1971). In GC-MS, both preparations showed a mixture of dihydroneopterin and tetrahydroneopterin. Therefore, we have emphasized that our results were due to that mixture, which will be referred to in this paper as « reduced neopterin ». Details on the chemical investigations and experiments will be published elsewhere.

Pterin-6-aldehyde (fig. 2). - Pterin-6-aldehyde was prepared according to the method of Visconti and Bieri (1971). Purification of the preparation was carried out by preparative paper chromatography on Whatman $3 \mathrm{MM}$ in the solvent ethanol: water, $1: 3$.<smiles>Nc1nc2c(c(=O)[nH]1)N=C(C(O)C(O)CO)CN2</smiles><smiles>Nc1nc2c(c(=O)[nH]1)NC(C(O)C(O)CO)CN2</smiles><smiles>Nc1nc2ncc(C=O)nc2c(=O)[nH]1</smiles><smiles>Nc1nc2nc(O)cnc2c(=O)[nH]1</smiles>

FIG. 2. - Pierins (2-amino, 4-oxo-pteridines) used in this study : A. Reduced neopterin, a mixture of dihydro-and tetrahydroneopterin (see Material and methods); B. Pterin-6-aldehyde; C. Isoxanthopterin.

Isoxanthopterin (fig. 2). - Isoxanthopterin was obtained from Fluka AG, Chemische Fabrik, $\mathrm{CH}-9470$, Switzerland.

A solution containing $1 \mu \mathrm{g}$ of pterin in $10 \mu \mathrm{l}$ of ammonia $0.01 \mathrm{M}$ per rat pineal was used. The blanks were treated in the same way without pterins.

\section{Results.}

Methylation of 5-HTP (fig. 1, step 1) was observed between 12 p.m. and 12 a.m. (fig. 3). If the pineals were incubated with reduced neopterin, significantly higher peaks of HIOMT activity appeared at 12 p.m. and 8 a.m. (fig. 3). The pineals incubated with pterin-6-aldehyde, however, showed a lower HIOMT activity during the diurnal 
cycle which was partly shifted to the daytime period, as compared with the untreated pineals (fig. 3 ).

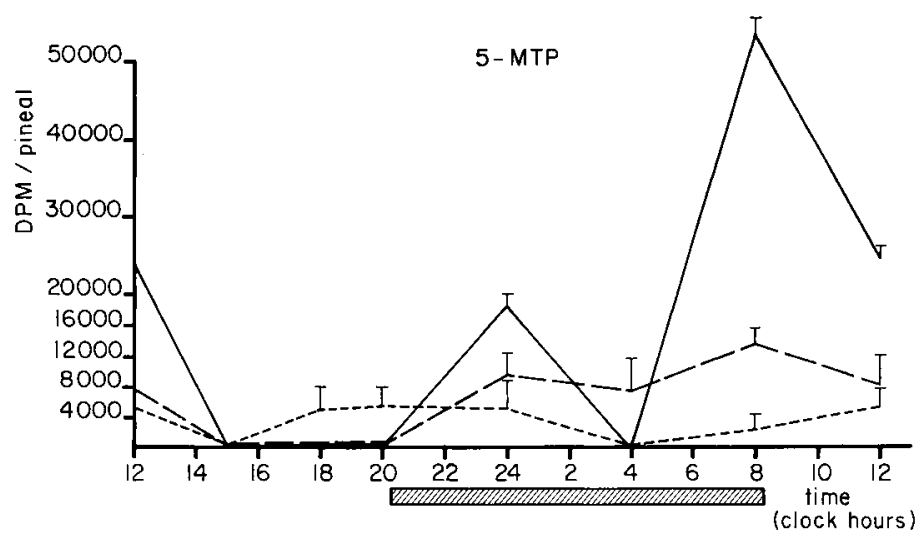

FIG. 3. - Influence of reduced neopterin (-) and of plerin-6-aldehyde (- - - ) on the circadian rhythmicity of 5-hydroxytryptophan methylation in the pineal of 42-day old male Wistar rats. Circadian methylating activity in pineal synthesis of 5-methoxythryptophan is indicated by a dashed line (- - ) ; these pineals were not incubated with a pterin but with a solvent only. Vertical bars represent the standard error of the mean ; DPM = desintegrations per minute; horizontal bar indicates the dark period.

Serotonin (5-HT) was methylated to 5-methoxytryptamine (5-MT) (fig. 1, step 2). Peaks of activity occurred during the daytime at 3 p. m. and 8 p.m. ; the peak of activity at the end of the night period ( $8 \mathrm{a} . \mathrm{m}$.) was remarkable (fig. 4). Reduced neopterin did not alter significantly the two activity peaks during the daytime but stimulated

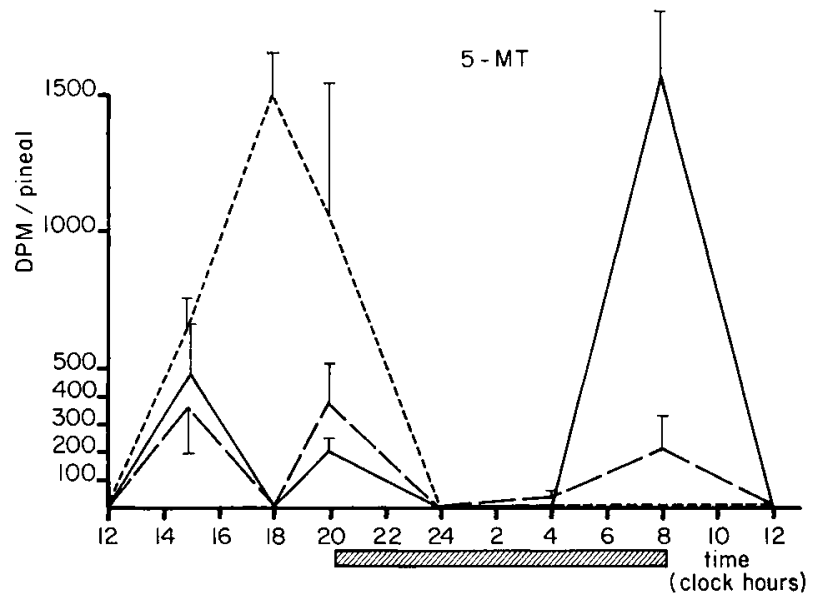

FIG. 4. - Influence of reduced neopterin (-) and of pterin-6-aldehyde (- - - ) on the circadian rhythmicity of 5-hydroxytryptomine methylation in the pineal of 42-day old male Wistor rats. Circadian methylating activity in pineal synthesis of 5-methoxytryptamine is indicated by a dashed line (- _ - ), pineals were not incubated with a pterin but with a solvent only. Vertical bars represent the standard error of the mean ; DPM = desintegrations per minute ; horizontal bar indicates the dark period. 
methylation markedly at the end of the dark period (fig. 4). This was in contrast to the effect of pterin-6-aldehyde, which inhibited the methylation in darkness but markedly stimulated it during the daytime (fig. 4).

5-HIAA methylation (fig. 1, step 3) occurred mainly during the night period from 12 p.m. to 8 a.m. without real peaks (fig. 5). If, however, the pineals were incubated with reduced neopterin, a significantly higher activity in the synthesis of 5-methoxyin-

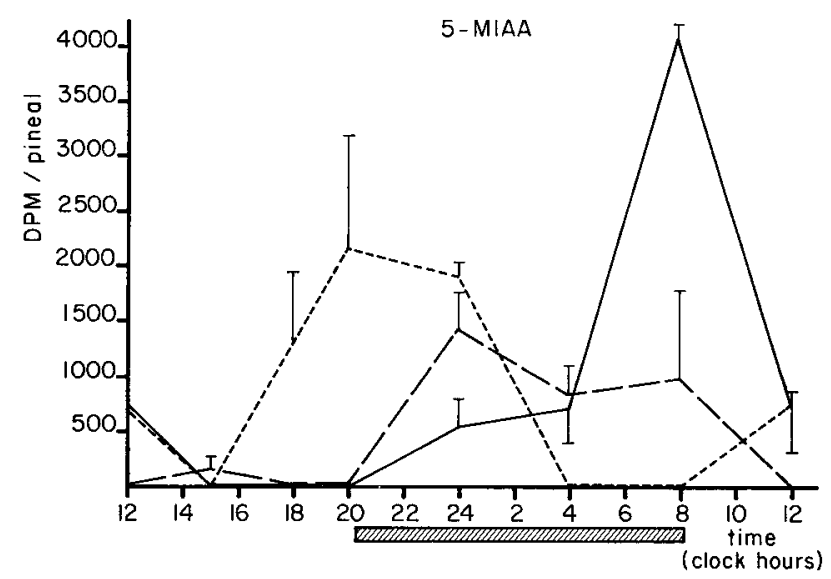

FIG. 5. - Influence of reduced neopterin (-) and of pterin-6-aldehyde $(--\rightarrow)$ on the circadian rhythmicity of 5-hydroxyindole-3-acetic acid methylation in the pineal of 42-day old male Wistar rats. Circadian methylating activity in pineal synthesis of 5-methoxyindole 3-acetic acid is indicated by a dashed line (_- - ), pineals were not incubated with a pterin but with a solvent only. Vertical bars represent the standard error of the mean ; DPM = desintegrations per minute; horizontal bar indicates the dark period.

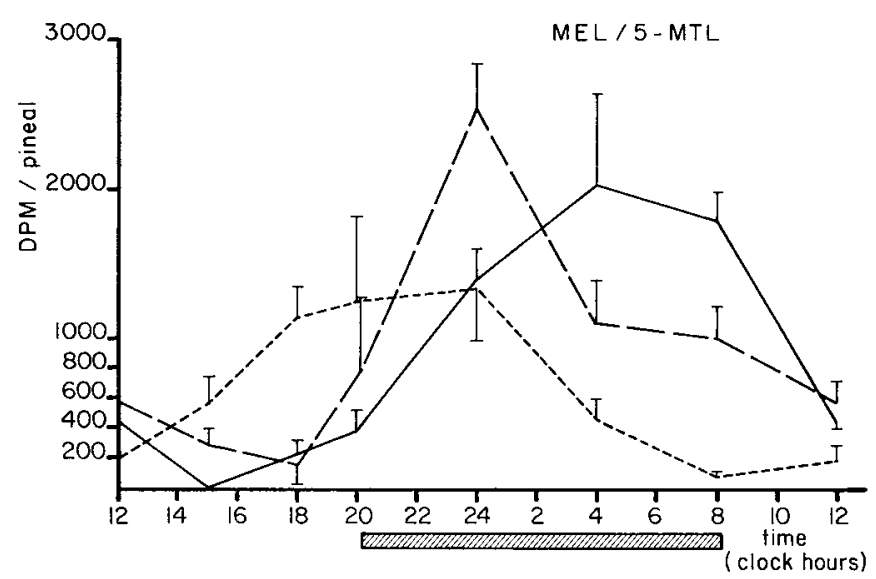

FIG. 6. - Influence of reduced neopterin (-) and of pterin-6-aldehyde (-- - ) on the circadian rhythmicity of $\mathrm{N}$-acetylserotonin/5-hydroxytryptophol methylation in the pineal of 42-day old male Wistar rats Circadian methylating activity in pineal synthesis of melatonin/5-methoxytryptophol is indicated by a dashed line (- - - ) ; pineals were not incubated with a pterin but with a solvent only. Vertical bars represent the standard error of the mean ; $D P M=$ desintegrations per minute ; horizontal bar indicates the dark period. 
dole-3-acetic acid (5-MIAA) occurred at the end of the night at 8 a.m. (fig. 5). The results of pterin-6-aldehyde were the opposite of those obtained with reduced neopterin, the methylating activity was partly shifted to the daytime (fig. 5).

The synthesis of melatonin/5-methoxytryptophol (mel/5-MTL) (fig. 1, step 4) occurred mainly during the night with a peak at 12 p.m. (fig. 6). Incubation with reduced neopterin did not cause a higher production of mel/5-MTL but a shift of the peak to a later moment in the dark period (fig. 6). Pterin-6-aldehyde showed the opposite effect : there was a partial shift towards the daytime.

To summarize these results, the effect of reduced neopterin on the methylation of all 5-hydroxyindoles can be characterized as a stimulation at the end of the dark period. A shift of the curve to a later moment was only observed for the methylation of N-acetylserotonin/5-HTL. Apart from serotonin methylation, the effect of plerin-6aldehyde on the methylation of all the other 5-hydroxyindoles can be characterized as a shift of the curves to an earlier moment. 5-hydroxindole methylation was not influenced by isoxanthopterin. The effect of that pterin on HIOMT activity was demonstrated for the syntheis of mel/5-MTL (fig. 7).

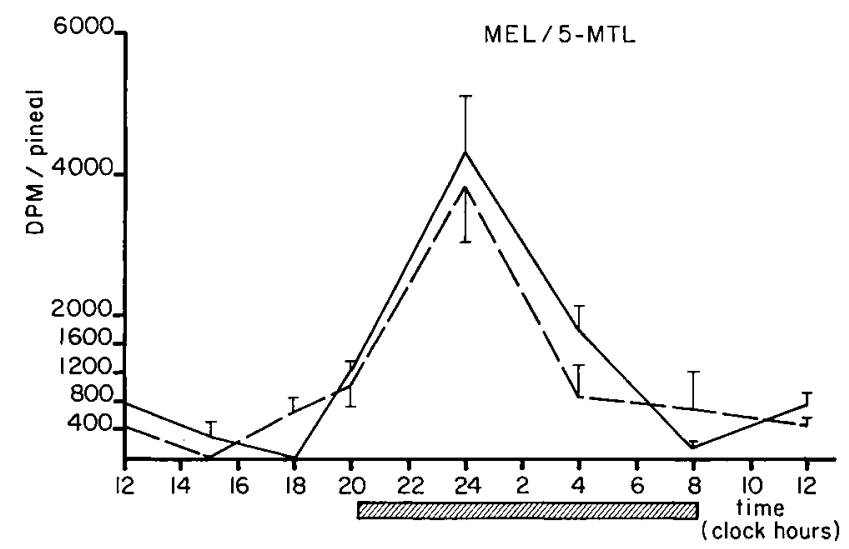

FIG. 7. - Influence of isoxanthopterin (-) on the circadian rhythmicity of N-acety/serotonin/5-hydroxytryptophol methylation in the pineal of 42-day old male Wistar rats. Circadian activity in pineal synthesis of melatonin/5-methoxytryplophol is indicated by a dashed line $(--\rightarrow)$; pineals were nol incubated with a pferin but with a solvent only. Vertical bars represent the standard error of the mean ; DPM = desintegrations per minute ; horizontal bar indicates the dark period.

\section{Discussion.}

Reduced neopterin is involved in the biosynthesis of dihydrobiopterin (Gal et al., 1976), which can be reduced to tetrahydrobiopterin. The latter is considered as a cofactor of tryptophanhydroxylase (Lovenberg and Victor, 1974). It may therefore be expected that reduced neopterin is involved in this way in indole metabolism. The present results show that the effect of reduced neopterin seems to be important for all HIOMT activities and is not limited to the methylated product of 5-HTP, as was expected according to Lovenberg and Victor (1974). The overall effect of reduced neopterin, as well as of pterin-6-aldehyde, on all methylating processes in indole metabolism seems to be direct, and cannot be attributed to an effect on the enzymatic activities 
preceding that of HIOMT. If this is true, the stimulation of 5-HTP and 5-HT methylation to 5-MTP and 5-MT by reduced neopterin suggests that the conversion of 5-HTP to 5-HT, as well as that of $5-\mathrm{HT}$ to $\mathrm{N}$-acetylserotonin, was slowed down (fig. 1). The result of reduced neopterin action therefore may be partial or total blockage of $\mathrm{N}$-acetylserotonin and, in consequence, melatonin synthesis.

To confirm this hypothesis, it is necessary to carry out experiments in which pterins are incubated at various times. No influence on the conversion of $5-\mathrm{HT}$ to 5-HIAA is known, but the stimulation of 5-HIAA to 5-MIAA may also point to a blockage from the mel/5-MTL pathway. Under the influence of reduced neopterin, there was a shift of the maximal HIOMT activity involved in mel/5-MTL synthesis to a later moment in the night. A similar shift was seen in an earlier study in which seasonal rhythmicity was proposed (Balemans et al., 1979). This could suggest a physiological role of pterin in the seasonal cycle.

Quay (1963) described a circadian serotonin rhythm with high concentrations during the daytime, probably caused by the synthesizing enzyme, 5-hydroxytryptophan decarboxylase, which is active only during the light period (Snyder ef al., 1965 ; Pellegrino de Iraldi and Rodriguez de Lores Arnaiz, 1964). In the present study, however, it is shown that under the influence of reduced neopterin, serotonin was highly meihylated at the end of the dark period. This means that serotonin, in contrast to the observation of Quay (1963), was present at night.

Pterin-6-aldehyde can inhibit the activity of xanthopterin oxidase (Lowry et al., 1949 ; Blakley, 1969), the enzyme which regulates isoxanthopterin synthesis. CremerBartels (1976) found that xanthopterin oxidase activity was higher in dark-adapted than in light-exposed rabbit eyes. As there is a biochemical resemblance between the eyes and the pineal, identical processes may occur in the pineal, and pterin-6-aldehyde could be involved in the light/dark rhythmicity of HIOMT. The results obtained in the present study also favor this hypothesis : pterin-6-aldehyde caused a shift of 5-HTP, 5-HIAA and N-Ac-5-HT/5-HTL methylations from the night toward the daytime.

Isoxanthopterin can prevent tetrahydrobiopterin (a cofactor of tryptophanhydroxylase) accumulation in squamous cell carcinoma (Kokolis et al., 1972), and it may thus be putatively concluded that isoxanthopterin serves as a «balance substance » for hydroxylations. The identical results obtained in our study with and without isoxanthopterin suggest that isoxanthopterin plays no role in the regulation of HIOMTactivities.

The influence of several pterins on the activity and the circadian rhythmicity of 5-methoxyindole synthesis suggest that pterins could be regulatory substances in indole metabolism and not simply inhibitory products, as was reported by CremerBartels and Hollwich (1978). As melatonin and 5-methoxytryptophol are involved in the regulation of reproduction (Wurtman et al., 1963 ; Mclsaac ef al., 1964), pterins may also be involved.

Reçu en novembre 1979.

Accepté en février 1980.

Acknowledgements. - The authors wish to thank Prof. Dr. J. C. van de Kamer and Dr. F. C. G. van de Veerdonk for their encouraging interest in these studies. They are very grateful to Dr. H. J. W. Spronck, Department of Analytical Chemistry, University of Utrecht, for recording the combined CG-MS spectra. 
Résumé. L'influence de trois substances dérivées des ptérines sur les fluctuations journalières de l'activité de l'HIOMT a été étudiée en octobre, sur des glandes pinéales isolées de Rat Wistar mâles âgés de 42 jours.

La méthode utilisée permet de déterminer séparément quatre activités de l'HIOMT. - L'isoxanthoptérine n'exerce aucune influence sur les variations journalières de toutes les activités de l'HIOMT étudiées.

- La néoptérine réduite, stimule durant la nuit les activités de l'HIOMT pour les substances 5-HTP, 5-HT and 5-HIAA. L'activité de I'HIOMT pour la combinaison N-acétylsérotonine/5HTL est retardée dans la phase d'obscurité.

- La ptérine-6-aldéhyde stimule durant le jour l'activité de I'HIOMT pour 5-HT. Les activités de I'HIOMT pour les substrats 5-HTP, 5-HIAA et $\mathrm{N}$-acétylsérotonine/5-HTL sont avancées dans le temps.

L'importance physiologique possible de quelques-unes de ces altérations est discutée.

\section{References}

AXELROD J., WURTMAN R. J., SNYDER S., 1965. Control of hydroxyindole-0-methyl transferase activity in the rat pineal gland by environmental lighting. J. biol. Chem., 240, 949-955.

BALEMANS M. G. M., LEGERSTEE W. C., van BENTHEM J., 1979. Day and night rhythms in the methylation of $\mathrm{N}$-acetylserotonin/5-hydroxytryptophol in the pineal gland of male rats of different ages. J. neural Transm., 45, 265-272.

BALEMANS M. G. M., NOORDEGRAAF E. M., BARY F. A. M., van BERLO M. F., 1978. Estimation of the methylating capacity of the pineal gland, with special reference to indole metabolism. Experientia, 34, 887-888.

BLAKLEY R. I., 1996. The biochemistry of folic acid and related pieridines. North-Holland Publ. Co., Amsterdam-London.

BROWNSTEIN M. J., HELLER A., 1968. Hydroxyindole-0-methyl-transferase activity : Effect of sympathetic nerve stimulation. Science, 162, 367-363.

CARDINALI D. P., LARIN F., WURTMAN R. J., 1972. Action spectra for effects of light on hydroxyindole-0-methyltransferase in rat pineal, retina and Harderian gland. Endocrinology, 91, 877886.

CREMER-BARTELS G., 1976. Pteridines in the mammalian retina and light effects, 861-870. In PFLEIDERER W., Chemisiry and biology of pteridines, Walter de Gruyter, Berlin-New York.

CREMER-BARTELS G., HOCKWIN O., 1963. Uber die Wirkung von Tageslicht auf den Stoffwechsel von Ratten-und Rinderlinsen. 65th Meet. German ophthalmol. Soc., Heidelberg, 314-316 (Abstr.).

CREMER-BARTELS G., HOLLWICH F., 1978. Effects of pteridines on melatonin biosynthesis of pineal gland and retina. Int. Symp. Chemistry and biology of pteridines (Abstr. VI).

FUKUSHIMA T., NIXON J. C., 1979. Reverse-phase high-performance liquid chromalographic separation of unconjugated pterins and pleridines, 35-36. In KISLIUK R. L., BROWN G. M. Chemistry and biology of pleridines. Developments in biochemistry, 4, Elsevier, North-Holland, New York-Amsterdam-Oxford.

GAL E. M., HANSON G., SHERMAN A., 1976. Biopterin. I, Profile and quantitation in rat brain. Neurochem. Res., 1, 511-523.

KAUFMAN S., 1967. Metabolism of the phenylalanine hydroxylation co-factor. J. biol. Chem., 242, 3934-3943.

KLEIN D. C., BERG G. R., WELLER J., 1970. Melatonin synthesis : adenosine 3'-5'-monophosphate and norepinephrine stimulate $\mathrm{N}$-acetyltransferase. Science, 168, 979-980.

KLEIN D. C., WELLER J. L., 1970. Indole metabolism in the pineal gland : A circadian rhythm in $\mathrm{N}$-acetyltransferase. Science, 169, 1093-1095.

KOKOLIS N., MYLONAS N., ZIEGLER I., 1972. Pteridine and riboflavin in tumor tissue and the effect of chloramphenicol and isoxanthopterin. Zeitschr. Nafurforsch., 27b, 292-295.

LEVINE R. A., KUHN D. M., LOVENBERG W., 1979. The regional distribution of hydroxylase cofactor in rat brain. J. Neurochem., 32, 1575-1578. 
LLOYD T., WEINER N., 1971. Isolation and characterization af a tyrosine hydroxylase co-factor from bovine adrenal medulla. Mol. phormac., 7, 569-580.

LOVENBERG W., VICTOR S. J., 1974. Regulation of tryptophan and tyrosine hydroxylase. Life Sci., 14, 2337-2353.

LOWRY O. H., BESSEY O. A., GRAWFORD E. J., 1949. Photolytic and enzymatic transformations of pteroylglutamic acid. J. biol. Chem., 180, 389-398.

MCISAAC W. M., TABORSKY R. G., FARRELL G., 1964. 5-Methoxytryptophol : Effect on estrus and ovarian weight. Science, 145, 63-64.

PELLEGRINO DE IRALDI A., RODRIGUEZ DE LORES ARNAIZ G., 1964. 5-Hydroxytryptophandecarboxylase activity in normal and denervated pineal gland of rats. Life Sci., 3, 589-593.

QUAY W. B., 1963. Circadian rhythm in rat pineal serotonin and its modifications by estrous cycle and photoperiod. Gen. comp. Endocr. 3, 473-479.

SNYDER S. H., AXELROD J., WURTMAN R. J., FISCHER J. E., 1965. Control of 5-hydroxytryptophandecarboxylase activity in the rat pineal by sympathetic nerves. J. Pharmac. exp. Ther., 147, 371-375.

VAN DER HAVE-KIRCHBERG M. M. L., DE MOREE A., VAN LAAR J. F., GERWIG G. J., VERSLUIS C., EBELS I., HUS-CITHAREL A., L'HERITIER A., ROSEAU S., ZURBURG W., MOSZKOWSKA A., 1977. Separation of pineal extracts by gelfiltration. VI. Isolation and identification from sheep pineals of biopterin : comparison of the isolated compound with some synthetic pleridines and the biological activity in in vitro and in vivo bioassays. J. neural Transm., 40, 205-220.

VISCONTI M., BIERI J., 1971. Uber Pterinchemie. Neue Synthesen von Folsäureanalogen. Helv. chim. Acta, 54, 2291-2297.

WARTMAN S. A., BRANCH B. J., GEORGE R., NEWMAN-TAYLOR A., 1969. Evidence for a cholinergic influence on pineal hydroxyindole-0-methyl-transferase activity with changes in environmental lighting. Life Sci., 8, 1263-1270.

WEISS B., 1968. Discussion of the formation, metabolism and physiologic effects of melatonin. Advanc. Pharmac., 6A, 152-155.

WURTMAN R. J., AXELROD J., CHU E. W., 1963. Melatonin, a pineal substance. Effect on the rat ovary. Science, 141, 277-278. 